The Event of a Stitch:

The Seamstress, the

Traveler, and the

Storyteller 


\begin{abstract}
5

Keywords: stitch; event; storytelling; exchange

of Anni Albers, whose assertion that all weaving traces back to "the event of a thread," together with Walter Benjamin's storyteller/ craftsman, and their fragmented and embellished story-fabric. This article will consider these legacies and their makers, seeking to expand the notion of stitch as a form for enlarged mentality. Works by Áine Phillips, Kirstie Macleod, and Chiharu Shiota will be drawn upon as a way by which to think of the event of a stitch as a cosmopolitan practice-a mode of practice which exists in each moment of encounter between needle, thread, and cloth.

of the residents, but together with them. These two points of departure necessarily involve the leaving behind of traces, a legacy. This article draws upon the legacy
\end{abstract}




\section{The Event of a Stitch: The Seamstress, the Traveler, and the Storyteller}

According to Slavoj Žižek, an event is "an effect that exceeds its causes": a point of rupture, after which everything is changed $(2014,5)$. An event, taken in this way, reframes its causes to include or enfold that change. Cause and

effect are thus not separated or even sequential, but rather elements that are conjoined and in permanent relationship with one another.

The event is a creative concept, continuing to enfold effect within itself, never fully completed, and never reversible, perpetually incomplete. In this sense, the event is the production of an indeterminate project; it is open to ruptures on the way, it depends upon such ruptures to which it gives rise and enfolds them as they appear. Where the predetermined project is already complete and thus does not require any additional elements for its completion, the indeterminate project is permanently open, contextual, relational, unpredictable, and contingent. Such a project moves forward, adjusts its trajectory, stops and re-starts suddenly. As the event unfolds, so it simultaneously enfolds its past within itself. The event, built upon repeated and enfolded ruptures, destabilizes the notion of traveling towards a destination, in favor of what Rebecca Solnit, in "Wanderlust: A History of Walking" (2014) refers to as "a movement" that sets the body in motion, embedding it among that which it encounters (Solnit 2014, 5).

Such a concept of an event as an ongoing process of unfolding and enfolding and effects casts an interesting light upon weaver Anni Albers' final lines in her Preface to "On Weaving" (1965), in which she wrote:

Just as it is possible to get from any place to any other, so also, starting from a defined and specialised field, one can arrive at a realisation of ever-extending relationships. Thus tangential subjects come into view. The thoughts, however, can, I believe, be traced back to the event of a thread. $(1965,15)$

Albers is intrigued by the interplay between beginnings, endings, and elaborations, revelling in the ways in which looking back allows her to "experience vicariously the exhilaration of accomplishment reached step by step" $(1965,52)$, but this eventful approach also enables her to more clearly reveal how the development of different weaves and different weaving processes and technologies can be traced back to the repeated under and over of warp with weft. Albers pursued the relation between surface and weave, focusing upon the foundational relationship between textile, mobilization, and cultural transit, suggesting through this an aesthetic of

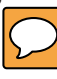


material surfaces, material objects that "can be lifted, folded, carried, stored away and exchanged easily" $(1965,48)$. This is Albers' "event of a thread."

The event of a stitch, drawing upon these themes, is about needle and thread passing through Albers' cloth, engaging in a tactical creation of material exchange as it does. As the thread passes through it visits, it lingers in another place as it travels, it is an invited visitor, a guest. As it takes its leave, it marks the trace of its passage, a legacy, a remnant of being together beyond, out in front of, in excess of, the visit.

This article seeks to expand the notion of the stitch as event that develops from a hand-held series of local movements into full-body articulation of stitching as a form for enlarged mentality. Setting stitch as simultaneously and separately event, visit and legacy as points of departure.

To visit is to spend time in another place, with its residents, to be introduced through their eyes and bodies, not in place of them, but together with them. Hannah Arendt drew on the concept of visiting in terms of "thinking with an enlarged mentality" $(1978,257)$, a mode for thinking that foregrounds and presupposes movement away from the self, towards the other, not in an occupying or colonizing manner, but in the role of the guest, the invited visitor.

The event, as a radical turning point, not only changes things in its wake, but changes the parameters by which that change is perceived and measured. This is the legacy of the event: its traces and marks left behind that evidence its occurrence, momentarily separated before becoming bound up within the causes of another event.

In order to expand the notion of stitch from these three points of departure-the event, the visit and the legacy-I will invoke the voice of the seamstress, the traveler, and the storyteller. That this article has its roots in conferences in both Detroit, US, and Margate, UK, is particularly important to this approach as both locations, in different ways, hold the promise and legacy of travel: they both focus upon that which is beyond ourselves.

As one travels, there is the marking and meeting of different cultures, sites for creating community together. This community is provisional and contingent: a precarious ecology built upon exchange and encounter. Marsha Meskimmon, in her introduction to "Contemporary Art and the Cosmopolitan Imagination" (2010) considers such encounters in terms of a community of space and subjects, mutually and repeatedly constructed through dialogue and dynamic exchange. In such a framing, or indeed re-framing, of cosmopolitanism, she locates the edges as spaces for "opening ourselves to others through imaginative engagement rather than through assimilation" $(2010,7)$. She builds outwards from Kwame Anthony Appiah's notion of the conversation: a thinking from the other's perspective that does not continue hushed invocations of difference, but suggests a form of dialogue that necessitates an imaginative, creative shift from the subject and becomes an aesthetics and ethics of openness towards the other "I," an echo of Arendt's "enlarged mentality." For Appiah:
Conversations across boundaries of identity-whether national, religious or something elsebegin with the sort of imaginative engagement you get when you read a novel or watch a movie or attend to a work of art that speaks from some place rather than your own. $(2007,85)$

Such imaginative engagement is a vital element upon which Meskimmon suggests a precarious ecology of belonging can be found. Thus, for Appiah, Meskimmon, and Arendt, the imaginative leap is radical and bold; it is a risky mode of engagement in that it is not predicated upon foundational structures, nor directed towards consensus, but rather it foregrounds and privileges being in community with another and others. It is an activating towards the other.

In her article, "An Aesthetic of Blackness: Strange and Oppositional" (1995), the writer bel hooks opens with a reflection upon her childhood home:

This is the story of a house. It has been lived in by many people. Our grandmother, Baba, made this house a living space. She was certain that the way we lived was shaped by object, the way we looked at them, the way they were placed around us. She was certain we were shaped by space. (1995, 65)

What is on first reading an expression of space and home and a house, very quickly reveals itself as the story of relationships, intimacy, storytelling, and remembering together. In this text, hooks reveals how family histories and everyday objects inscribe themselves upon each other-each teaches the other 
to see, to tell and to re-tell: how to understand oneself. In this then an aesthetics of openness moves beyond an idea and a construct, outwards towards that other through relationship, through looking, being, and becoming together. This is Meskimmon's precarious ecology: its precarity lies not in the threat of collapse, but rather within resistance to fixedness and closure, against boundaries and borders that constrain and contain.

Here, I want to explore the relationship between the seamstress stitching, the storyteller recounting the tale, and the traveler moving between home and away and the encounters along the way. To do so involves Sarat Maharaj's "thinking through textiles" $(2001,7)$ that suggests stitching, particularly by hand, as a means for thinking about oneself, one's place in the world, and as a means for constructing concepts that move outwards from oneself. In this sense, the act of stitching becomes a tactic that is at once conceptual, subversive, and ethical.

"Thinking through textiles," as conceived by Maharaj, foregrounds "openended-ness" and "undecidability" in the repeated doing and undoing, Penelope-like, that echoes thinking, remembering, and storytelling: the attentiveness to connections and reverberations. As needle and thread pass in, through and back, so there is a focus upon ideas in flux: the process of their formation. Stitching and making seams offers agency, the potential for reflection, re-purposing, remembering, and imagining. As Bernard Herman writes of the architecture of Gee's Bend quilts, they “create tangible spaces and places where their builders remember ancestors and imagine the future" $(2006,218)$. As the quilts were formed and encompassed the communal aesthetics and social and spiritual language of the people who made them, as needle and thread passed to and fro, so they become open to mediate the space of the individual within a cosmopolitan community.

A woman sits stitching a dress. She has selected the pattern after much poring through the large hard-cover books in the shop, finally deciding upon this one, imagining herself dancing and the movement of her hips emphasized by the shape and fit of the skirt. She has carefully chosen the fabric, red silk satin, for its lustre and sheen in the evening light. She will stitch it by hand to ensure the fabric is not marked by the sewing machine feed; there will be no puckering from tension slipping or blunt needle.

As needle and thread pass to and fro between the layers of the fabric she is carefully stitching, so she feels the weight and flex of the cloth. It is woven with just a touch of elastane so that it will move and sway with her body, shimmer and shine. The seamstress looks forward and back to the other options, to the evening to come and back into focus comes the fabric and the placing of each stitch.

Needle and thread move between layers of fabric, drawing them firmly together in the action and activity of making the seams. They turn flat pieces of fabric into the moving, swaying garment on the woman's dancing, swaying body. Needle and thread graft sleeve onto bodice, bodice onto skirt, zip onto opening and so bring individual elements together to form a communal whole. she is an ideological space invested with beauty, desire, loss and longing. The work is sensitive, poetic and challenging ... (http:// ainephillips.com)

Describing some of the ideas bound up in her work, the Irish artist, Áine Phillips explains that in her performances:

without pre-constructed dramatic content, narrative or characterisation, the free-form improvisations ... were liberated from the conventions of theatre and without the traditional beauty or a necessary focus upon the body, the performances were freed from the conventions of dance. (Phillips 2012, 65)

In Red Weight (2013), Phillips constructed a dress whose skirt was made from 600 pieces of used red clothing which she pulled as a train through the streets of Krakow. She progressed slowly, purposefully and as if leading a grand elegant, procession.

The performance, fraught with its own practical difficulties of journeying with a street-length train becomes a metaphor for the memories, dreams, and gathered stuff that accompany our passage in life. Sometimes we progress readily, at other times the train catches or bunches up and other need to help us to become free again to move forward. Phillips suggests the everyday moments that mingle with the more momentous memories, often undetected or unconscious that form our habit-filled lives. This social fabric is her material.

In this work the needle and performer becomes nomad, an existence beyond the organized space of the cloth, but bound up within it 
in the sense that the nomad has a territory, customary paths, moving from point to point (water points, dwelling points, meeting points and so on). But where for the sedentary or static dweller, the points determine the paths, the nomadic way reverses this focus and the paths are subordinate to the points. For the seamstress, then, the pattern choosing, fabric, and evening event are the points to her stitching paths-her needle, thread, and stitching hands are her way of being between these points, her goal or focus of attention is to continue to move within and the process of creation prioritizes itself over the finished garment or event for which it is intended.

Áine Phillips' Red Weight is a performative work. As her body moves, followed by her train, she occupies both horizontal and vertical planes, setting her body and dress as needle and thread passing through the fabric; this fabric is the crowded city streets of Krakow, the space of her progress, the world she observes and experiences. Therefore, the work becomes the seaming, the threshold and turning point across the surface of the garment, shaped and manipulated in its joining to enable that body within to move and sway to the music.

The music of Red Weight is not the rhythmic beat of a band, nor the heaving bass of a club, but that of the city, the people, and their bodies; of her environment, but it is silenced in the photographed records and we can only read it through the images of the bodies. Her dancing is her movement in relationship to the crowded city streets. Her passage becomes the physical expression of movement in time. Through this movement space is also opened up.

In shifting to the nomadic pathpoint-path framework for thinking, Phillips destabilizes and de-centers the notion of movement through; her body becomes the barometer or metronome marking time and space.

As needle and thread pass to and fro between the pieces of cloth, forming the dancing dress, so the cloth passes over and under that needle and thread, moving between fabric and garment, weaving and dancing, body and body, forming a seam or join and a threshold across time and space, acting as witness in the midst. Here, Phillips becomes a needle that gauges reality, a clock's hand registering the passage of events that she herself performs.

\section{The Storyteller}

The journey always begins with packing. Selecting and deciding, choosing, unchoosing, and re-choosing: this one or that one, which of these, two or three of these? Have I enough? Have I too much? Will it all fit?

In this way the storyteller sets out on a journey, seeking new experiences, new views of the world to bring back and share: people and things seen, heard, smelled, heard of, just missed, imagined, and never found ... Layer upon layer, fragments gathered together for later reflection, contemplation, and telling.

Each telling of the journey is an act of repeating, fragmenting, joining, and embellishing-it is all in the telling. However, as Walter Benjamin reminds us, it is also all in the hearing as these fragments and parts of fragments and partly joined fragments we are themselves into the listene similated now into their story.

A sto $y$ is different. It does not exparld itself. It preserves and concentrates its strength and is capable of releasing it even after a long time ... the more natural the process by which the storyteller forgoes psychological shading, the greater becomes the story's claim to a place in the memory of the listener, the more completely it is integrated into his own experience, the greater will be his inclination to repeat it to someone else someday, sooner or later.

(Benjamin 1999, 90)

Thus the fragments form a story-fabric: each one being brought into being through its own performance, a performance that relies upon exchange between storyteller and listener. A performance of companionship. Sarah Ahmed uses the idea of the second skin to examine what happens when the person changes location through migration, suggesting it requires "a splitting of home as a place of origin and home as a sensory world of everyday experience ... a spatial reconfiguration of an embodied self: a transformation in the very skin through which the body is embodied ... an expansion and contraction of the skin" (Ahmed 1999, 90).

In turning to skin by way of a metaphor and the notion of contraction and expansion of that skin in the process of relocation, or here traveling, Ahmed emphasizes the heightened sensitivity at the surface that comes with a new location or traveled. How it looks, smells, sounds, and feels intrudes into and onto the body-everything becomes unstable and the body must learn to recalibrate itself. This 
is the stuff for storytelling; there is a sense of seeing in the world, being at the center of the world and yet the traveler is in some way hidden from the world. It is a sensitive state: rooted in the correct time through bodily presence, whilst the mind is caught between the origin and new space-in between. It is a space

for remembering and imagining: a space for storytelling to take root. In this space, packing and journeying and the experience of that journey become entwined: the activity of sifting and selecting, the telling and re-telling intertwine.

The sensitive, dislocated body is both liberated from living-as-usual and displaced or alienated and the act of storytelling becomes a tactic or strategy for expanding the notion of "at home" and the creation of community. Storytelling thus becomes a mechanism for dealing with the home-away schism and the sensitive body becomes rehabilitated to itself through the crafting of the story.

Barocco (2009-2019) is a decade-long embroidery project by British artist Kirstie Macleod that is centered around a single red dress. In this work/performance, the embroiderer sits within her glass box, clothed in a multi-layered red, silk dress, stitching and embellishing that same dress on over 50 different occasions, in over 50 different locations. Since 2009, the dress has traveled around the world being continuously embroidered and added to by 50 different participants to date. The title comes from the ancient Portuguese word for a "rough or imperfect pearl," baroccois.

As this traveling, active, growing work makes its journey, Macleod's dress becomes storyteller, story, and listener, leaving traces of its presence through the photographs, documentation, and memories of those who have worn and stitched, viewed, and curated, packed, and unwrapped, heard and read of it: all travel with it.

The dress, too, as it journeys between people and places, changes and grows, carrying marks of its journeys and the journey-creators. As the dress becomes storyteller, story-fabric, needle, and thread, changed and changing throughout its journey and journeying, it expands and contracts. The embroidery, the threads, the dress and the embroiderers create a physical and metaphorical network or networked community, but its center, the dress, moves and changes.

MacLeod's dress proposes a hypothesis of a way of becoming community through generous encounter. As storyteller, the embroidered dress-in-production inscribes the body of the wearer within spatial production and from within its box destabilizes and reconceptualizes the occupation of that space as well as the occupation within that space. MacLeod's stitching woman facilitates female belonging through the bodily action of stitching, embroiders itself into existence.

The stitching, traveling body (or indeed bodies) suggest Solnit's "amateur acts" $(2014,4)$, but also the bodily labor that produces. The bodily act of walking, for Solnit, "moves through space like thread through fabric, sewing it together into a continuous experience-so unlike the way air travel chops up time and space and even cars and trains do" $(2014,15)$. In this way the stitching body and stitched dress immerse the bodies in and through space and place. The dislocated, sensitive body makes its journey, tells its story, creates itself. It destabilizes vision as monocular, emphasizing the bodily and cultural production of the subject in these actions of making. Meskimmon's "aesthetics of pedestrianism" (1997, 7) facilitates the production of identity and subjectivity for the woman through her own mimesis, enabling the stitching woman to become a participant on her own terms.

Such a mode of production is about the com-, or with, of companionship: it is collaborative and collective. The storytelling dress is a generous encounter built upon opening out and onto its listener. MacLeod's dress thus frames activation, authorship, and community as it travels between its 50 embroiderers, located in 15 countries, with multiple audiences, telling its multiple story, sewing together a continuous story.

\section{The Traveler}

Finally, the red silk dress is placed on the top of the open suitcase, ready to be secured with the other necessities for the journey. It is the last thing to be packed and the first to be unpacked upon arrival, to reduce its creases and to be prepared for the event.

Luggage, suitcase, rucksack, bag-all signify movement and the unbounded space of travel. These are the containers and safekeepers set amid a destabilized existence. Hamid Naficy, writing in "An Accented Cinema: Exilic and Diasporic Filmmaking" (2001) notes: 
every journey entails a return, or the thought of return. Therefore, home and travel, placement and displacement are always already intertwined. Return occupies a primary place in the minds of the [traveller]. (Naficy 2001, 229)

Naficy's concept of an "accented cinema" is concerned with the different forms of cinema produced by exilic, diasporic and postcolonial ethnic artists, producers and filmmakers, primarily resident away from what they would identify as their country of origin (2001, 11ff). A common theme is reference to the "homeland," a theme Naficy draws upon in framing this field of research. What is important here, and can be considered more broadly in terms of the traveler, together with the migrant, exile, and diasporan, is the notion of a dialogue with the home and host societies, demands and expectations of the sensitive body. This is not to collapse Naficy's accented cinematic practices into that of anyone moving beyond their own home, but it is the shared sense of a "double consciousness" (2001, 22) that his thinking highlights that is particularly interesting here.

To think of an "accented cinema" in linguistic terms is to foreground pronunciation and emphasis rather than vocabulary, structural and grammatical elements of language usage. Sometimes language spoken heavily accented is described as "thick" of "thickened"; the listener must concentrate and listen more attentively, assimilating the form and meaning into their own linguistic constructs to fully comprehend what they hear.

This returns the traveler to the performative element of travel. If every journey "entails a return, of the thought of return," then leaving is a performance that intertwines arrival with return. They enfold together the experience of travel and the changes it invokes. Like the needle and thread passing to and fro, back and forth between the pieces of cloth in forming the seam, so the traveler draws these elements together into a continuous, but nonlinear form. It is an accented form, thickened at the site of the seam created, at the site of the sensitive body moving through space and time.

Japanese artist Chiharu Shiota takes her viewers on a journey, the point from which they set sail is not precise; perhaps it is her Berlin residence, her Japanese family home, the Japanese Pavilion in Venice, perhaps somewhere else. In the 2015 Venice Biennale, she installed a large web of red threads, encompassing and trapping a boat and an uncountable number of keys. Shiota is a Japanese-born artist, a Berlin resident, and the keys have been donated from across the world; we do not know where the thread and boat have been sourced. The Key in the Hand (2015) shifts from a title to a promised truth.

In this installation, the objects (boat and keys) are caught up within the threads; it as if they are stitched into the gallery space. Suspended in this way, they offer memories, opportunities and hope. Keys open and unlock; they are the promise of entry. They also raise the question of what lies beyond? They question who is locking and unlocking? The boat, too, offers the journey, the return, the connecting of people across time and space, rough seas and becalmed waters.
The Key in the Hand is the travelers' tale; it is concerned with departures, arrivals, displacement, and rétrouvement. This is accented space, curated and thickened by the various elements. As each key becomes the focus of attention, it takes center stage, embellishing and cutting away through the web of connections.

Within this pulsating, breathing, moving red web or sea of threads, the boat travels. There is something contingent, precarious in Shiota's installations. They appear to be awaiting instructions for packing and travel, and in the same breath, it is as if the suitcase exploded, sending its contents across the gallery. Like the traveler herself, they draw meaning from their context, but simultaneously they give meaning to their context, they are The Key in the Hand.

Shiota uses the concept of entrapment and mass communication, inserting these notions into each new space as a means by which to initiate public possibility, to consider the body's relationship with a place, to temporarily transform and sensitize that place through drawing people to it, drawing them together as community. She calls attention to the relations between individuals, to their generous encounter one with another. As Shiota stitches the boat into the gallery, entrapping on the one hand, but allowing it safe passage on the other, so the viewers become both landing points and fellow travelers; they are accent points, moments of thickening where the concentration needs to intensify as the one body engages with the other.

So, with each journey, each new point of arrival and departure, the 
boat, the keys, the threads, and the dresses leave their traces. Like Macleod's dress, this is in the form of the photos, the videos, the performances, and conversations that surround it in each place and in the memories and relationships created, secured, and cemented there. These travel together with the work-sometimes ahead of it as messengers, sometimes the installation does not make the same physical journey as these when plans change, plans fall through, sometimes a new site has little pre-warning, sometimes it becomes part of something else. The work's trace becomes a form of back-room operator and forward-thinking event manager: it is the paradigm of prefiguration. The equivalency between work and trace is continuous, like Solnit's bodily acts, and so each engages in a flow of mimesis towards the other, decentring and thus refusing singular readings. The trace and the work together evoke their origins, but all the while they become Maharaj's "undecideability." Like the stitching needle, the threads move to and fro, forward and backwards across the gallery, drawing the elements together into a seamed whole. There is thickening, or accenting at the joins. Like the red silk dress, these seams allow for the body to inhabit and move within it. Shiota creates an event with her stitches, they pass to and from across the gallery, seemingly disordered, but working together to create coherent passageways and gathering spaces for the viewers. The Key in the Hand becomes Žižek's indeterminate project, leaving a legacy out in front if itself in a dynamic of exchange.

As the traveler prepares to return home, she gathers together her belongings that have taken up temporary residence in the hotel room and guest room. Packing to return is a changed activity from the outward journey; the dress is now worn and can be laundered carefully back at home. Additions need be found space: gifts, purchases, and the gathered ephemeral of travel. There are also subtractions: tights laddered, tissues and toiletries used, a scarf dropped and lost, gifts given. This altered arrangement, reframing the items and changed priorities, marks the trace of the traveler upon herself. These traces are the tangible reminders of the journeying, they attach themselves to the key vectors of travel: tangibility, fragmentation, memory, and place. Together these vectors create a matrix that articulates a kind of pact between the body and world within which traveling sensitizes it to.

Traveling, thus, hovers or balances precariously between the absolutely immediate and the significantly delayed. The immediate lies in unscripted and unplanned interactions in the moment: between artist and viewer(s), viewers and threads, artist and keys, and so on. These are bodily encounters. The body of the work and the body of the viewer become sensitized towards one another within the intimacy of the space Shiota creates in the gallery. The threads stretch themselves out in front, over the heads and around the sides of the viewers, silently corralling them through the exhibition. The delays or deferrals occur in the spread of knowledge of the work: in the press releases, publicity, and advance planning. These sit out in front, creating anticipation, expectation, hopes, and anxieties. The images, reviews, reflections, interpretations, critiques, and recalled encounters act first as evidence of something that was. These prefigurations and traces, like the packed suitcase, give plasticity to the work, these are the effects that follow on from the rupture that travel brings about.

These are the new pieces stitched into and onto the story-fabric. As the traveler and the seamstress, together with the storyteller, return home, they have added to their story-fabric. They have new embellishments and new trajectories for their tales and their stitching. Through the agency of art-making they have been part of a precarious ecology. As Meskimmon suggests, this is an ecology built upon exchange and encounter and as such it is an ecology that can only be changed and changing, continued, but not preserved.

As needle and thread and cloth pass through each other in the forming of the seam or join, so they engage in a tactical creation, opening out and onto others in mutual exchange.

\section{References}

Ahmed, Sara. 1999. "Home and Away: Narratives of Migration and Estrangement." International Journal of Cultural Studies 2 (3): 329.

Albers, Anni. 1965. On Weaving. Middletown, CT: Wesleyan University Press.

Appiah, Kwame Anthony. 2007. Cosmopolitanism: Ethics in a World of Strangers. London: Penguin.

Arendt, Hannah. 1978. The Life of the Mind: Thinking: Vols 1\&2. Translated by Mary MCarthy. San Diego, CA: Harcourt Publishers Ltd. 
Arnett, Paul, William Arnett, Bernard Herman, Maggi Gordon, Diane Mott, Dilys Blum, Lauren Whitley, Amei Wallach, and Joanne Cubbs. 2006. Gee's Bend: The Architecture of the Quilt. 1st ed. Atlanta, GA: Tinwood AQQ7 Books.

Benjamin, Walter. 1999.

Illuminations. London: Pimlico.

hooks, bel. 1995. "An Aesthetics

of Blackness: Strange and

Oppositional." Lenox Avenue: A

Journal of Interarts Inquiry 1: 65-72.

doi:10.2307/4177045.
Maharaj, S. 2001. "Textile Art - Who are You?" In Reinventing Textiles, edited by Janis Jefferies. Winchester: Telos.

Meskimmon, Marsha. 1997. Engendering the City: Women Artists and Urban Space. London: Scarlet Press.

Meskimmon, Marsha. 2010. Contemporary Art and the Cosmopolitan Imagination. 1st ed. London; New York: Routledge.
Naficy, Hamid. 2001. An Accented Cinema: Exilic and Diasporic

Filmmaking. Princeton, NJ: Princeton University Press.

Phillips, Áine. 2012. "Human Difference." PAJ: A Journal of Performance and Art 35 (1): 64-67.

Solnit, Rebecca. 2014. Wanderlust: A History of Walking. London: Granta.

Žižek, Slavoj. 2014. Event: Philosophy in Transit. London: Penguin. 